$\begin{array}{ll}\text { NAMA } & : \text { SHANTY KARINA } \\ \text { NPM } & : 175100051 \\ \text { PROGRAM STUDI } & : \text { SISTEM INFOMASI } \\ \text { MATA UJI } & : \text { STRUKTUR DATA } \\ \text { DOSEN } & : \text { ARIE SETYA PURA,S.KOM.,M.T.I }\end{array}$

\title{
PERANCANGAN STRUKTUR DATA YANG EFISIEN UNTUK PEMROGRAMAN
}

\section{ANALISIS JARINGAN}

\section{ABSTRAK}

Pada penelitian kali ini telah dirancang Tipe Data Abstrak (ADT) untuk menyimpan data data matriks yang berukuran dan berkapasitas besar sesuai dengan computer.

Program ini bermanfaat untuk memecahkan masalah jaringan dengan cara yang tepat dan memecahkan setiap langkah demi langkah.

\section{PENDAHULUAN}

Analisis jaringan merupakan suatu masalah dalam penelitian operasional yang mencakup rute pendek,persoalan minimasi jaringan,dan persoalan aliran maksimum. Memecahkan masalah tentang analisis jaringan secara manual itu memang sangatlah sulit dan sangat beresiko tinggi sehingga computer memiliki alat bantu untuk memecahkan masalah ini dengan mudah.

Pembuatan program untuk memecahkan masalah analisis jaringan ini menggunakan memori yang cukup besar untuk memasukkan data dan memproses data tersebut.

Yang menjadi masalah perancangan ADT adalah bagaimana menggunakan computer dengan memori seminimum mungkin tetapi dihasilkan dengan semaksimum mungkin.

ADT ini dirancang sedemikian mungkin agar dapat menghasilkan rancangan yang baik dan sempurna.

\section{TUJUAN PUSTAKA}

Suatu jaringan tersebut dihubungkan dengan suatu titik titik node,dan biasanya nih node -node itu dilambangkan menggunakan huruf ataupun angka.

Pada persoalan rute pendek ini,yang mempengaruhi node adalah jarak dari rute pendek tersebut.. Dan cara memecahkan masalah rute pendek itu,kita harus menggunakan 
algoritma Dijkstra atau algoritma Floyd (Dimyati, 1992) (Wirt, 1976). Nah biasanya algoritma Dijkstra ini digunakan untuk node-node dalam rute pendek ke node lainnya... Dibawah ini bias kalian lihat nih contoh dari algoritma Dijkstra atau algoritma Floyd :

procedure Floyd (n:integer

$\operatorname{var} A$ :array[1..n, $1 . . n]$ of real;

C:array[1..n, $1 . . n]$ of real);

var i,j,k:integer;

begin

for $i:=1$ to $n$ do

for $j:=1$ to $n$ do

begin

$\{$ salin nilai matriks $\mathrm{C}$ ke $\mathrm{A}$ \}

$A[i, j]=C[i, j] ;$

\{ set matriks path \}

Path[i,j]:=0;

end;

for $k:=1$ to $n$ do

for $i:=1$ to $n$ do

for $\mathrm{j}:=1$ to $\mathrm{n}$ do

\{ periksa apakah didapatkan \}

$\{$ jarak yang lebih kecil $\}$

\{jika melalui $\mathrm{k}$ \}

if $(A[i, k]+A[k, j])<A[i, j]$ then

begin

\{perbarui matriks $\mathrm{A}$ \}

$A[i, j]:=A[i, k]+A[k, j] ;$

\{ catat lintasan/jalur \}

Path $[i, j]:=k$;

end; 
end; $\{$ procedur $\}$

Nah C itu untuk menyimpan jarak antar node secara langsung.jika $A$ itu untuk menyipan node dengan jarak pendek..

Inti dari algoritma Floyd ini yaitu untuk mencari jarak terdekat dari node node tersebut dengan cara menghubungkan antar node satu dengan node yang lainnya.

STRUKTUR DATA GRAPH

Data graph adalah suatu ADT yang digunakan untuk mengatasi masalah jaringan. Data graph ini bias dituliskan:

const

MaxNode = 100;

type

Graph $=$ object

$\{$ data $\}$

$\mathrm{N}$ : integer;

A : array[1..MaxNode,

1...MaxNode] of real;

$\{$ metoda manipulasi data $\}$

procedure

function ..........

end;

$\mathrm{N}$ ini digunakan untuk menyimpan banyaknya node. Nah jika $\mathrm{A}$ itu merupakan Array dua dimensi yang berfungsi untuk menyimpan jarak antar node tersebut.

Perancangan Input Program

Perangkat lunak ini menerima data masukkan berupa data file dan juga keluarannya itu bisa berupa data file text yang bisa menyelesaikan masalah langkah demi langkah.

Perancangan Obyek TDataMatrixReal

Ini merupakan inti dari pemecahan masalah. Berisi data dan metoda untuk memanipulsi data data matriks yang berukuran besar. Data ini disimpan di memori dinamis yang digabungkan dengan menggunakan gabungan dari array dan pointer. Kerangka dalam obyek ini adalah :

const 
TDataMatrixMaxElement $=600$;

TDataMatrixMaxBlock = 600;

type

TDataMatrixRealData $=$

array[0..TDataMatrixMaxElement-1]

of real;

TDataMatrixRealPtr =

${ }^{\wedge} T$ DataMatrixRealData;

TDataMatrixReal $=$ object

$\{$ data $\}$

row, col, block : word;

Data : array

[0..TDataMatrixMaxBlock-1] of

TDataMatrixRealPtr;

$\{$ metoda $\}$

constructor Init

(xrow,xcol:word);

destructor Done;

procedure SetValueAll (D:Real);

function Get (i,j:word) : Real;

procedure Put (i,j:word; D:Real);

end;

Perancangan Obyek TGraph

Ini digunakan untuk menangani data jaringan. Tugas utama dari obyek ini untuk mengalokasikan memori untuk menyimpan data jaringan. Kerangka obyeknya adalah sbb :

const

GRAPHMAXNODE = 600;

type 
TGraph $=$ object

$\mathrm{n}$ : integer;

A : TDataMatrixReal;

constructor InitFromFile

(FileName:string);

constructor InitCopy

(var Graph:TGraph);

destructor Done;

function Get (i,j:word) : Real;

procedure Put (i,j:word; D:Real);

end;

HASIL DAN PEMBAHASAN

Tampilan antar muka ini sudah dirancang secara visual yang sudah disediakan oleh Delphi. Interface pada program ini sudah dirancang sedemikian rupa agar mudah untuk digunakan.

\section{KESIMPULAN DAN SARAN}

Jadi kesimpulan dari ini semua yaitu :

1. Analisis jaringan merupakan suatu masalah dalam penelitian operasional yang mencakup rute pendek,persoalan minimasi jaringan,dan persoalan aliran maksimum.

2. Pembuatan program untuk memecahkan masalah analisis jaringan ini menggunakan memori yang cukup besar untuk memasukkan data dan memproses data tersebut.

3. Perancangan type tgraph Ini digunakan untuk menangani data jaringan. Tugas utama dari obyek ini untuk mengalokasikan memori untuk menyimpan data jaringan.

\section{SARAN}

- Perlu dikembangkan struktur data graph yang mampu memanfaatkan penyimpan eksternal ( disk) sebagai tempat pemrosesan sementara ( temporer) untuk memecahkan masalah jaringan yang besar yang datanya tidak cukup disimpan di memori internal. 